\title{
Desfazer/Refazer a condição pós-conceitual
}

\author{
Éric Alliez* \\ para Peter Osborne
}

RESUMO: Este artigo visa mostrar como os trabalhos de Daniel Buren e de Gordon Matta-Clark uma desconstrução ao mesmo tempo dos limites da autonomia da arte e da arquitetura. Mas se, por um lado, a crítica da autonomia da arte, que incorpora o nível exclusivo/inclusivo da crítica da arte conceitual - feita pelo "trabalho in situ" de Daniel Buren -, acaba por provocar uma situação de não-arquitetura na medida em que ele trabalha sob e sobre a arquitetura; por outro, a radicalização desta situação só se dará efetivamente nas operações feitas por Matta-Clark quando este ataca os fundamentos mesmos da arquitetura em nome de uma "anarquitetura". Comunicação apresentada na Jornada de estudos La condition postconceptuelle — De l'art contemporain que aconteceu na Universidade Paris 8, no dia 9 de maio de 2014.

PALAVRAS-CHAVE: in situ, anarquitetural, diagramático

RESUMÉ: Cet article vise à montrer la façon dont les travaux de Daniel Buren et Gordon Matta-Clark réalisent une déconstruction à la foi des limites de l'autonomie de l'art et de l'architecture. Néanmoins, si, d'un côté, la critique de l'autonomie de l'art, qui incorpore le niveau exclusif/inclusif de la critique de l'art conceptuel réalisé par le "travail in situ" de Daniel Buren -, aboutit à provoquer une situation de non-architecture dans la mesure où il travaille sur et sous l'architecture; d'un autre côté, la radicalisation de cette situation ne viendra effectivement que dans les opérations réalisés par Matta-Clark, puisqu'il attaque les fondements mêmes de I'architecture au nom d'une "anarchitecture». Cette communication a été présenté dans la Journée d'études sur La condition postconceptuelle — De l'art contemporain qui a eu lieu dans Université Paris 8, le 9 mai 2014.

MOTS-CLÉS: in situ, anarchitectural, diagrammatique

\footnotetext{
* Éric Alliez é professor da cadeira de Filosofia e Criações Contemporâneas em Arte da Universidade Paris 8, Éric Alliez foi Professor convidado da Universidade do Estado do Rio de Janeiro (1988-1996). Desde 2010, é professor de Filosofia Francesa contemporânea da Kingston University. É membro fundador da revista Multitudes, a qual ele deixou em 2009.
} 
1. A condição pós-conceitual enuncia a função constituinte da crítica da arte conceitual para uma arte $=x$, que consequentemente não vem exatamente depois.

2. Não é tanto a crítica da arte conceitual para e em si que importa, mas o nível inclusivo/ exclusivo (uma disjunção inclusiva?) pelo qual, em tempo real, um Daniel Buren a eleva a um modo de fundo comum com o questionamento de todas as formas de autonomia da arte que ele exporá, numa desconstrução continuada dos seus "limites formais e culturais", no "trabalho in situ". Irredutível a tudo o que pôde ter sido entendido em termos fenomenológicos do site specificity, o in situ valerá como "proposição" de reabertura ontológica da arte como questão - e como efeito do deslocamento pós-conceitual da antinomia entre o modernismo e o antimodernismo duchampiano.

3. Processo que Gordon Matta-Clark levará ao seu acme ao atacar os fundamentos da arquitetura em nome de uma "anarquitetura", a qual submeterá a sintaxe documental da arte conceitual a uma "ANARCHYTORTURE" — tal como se pode ler neste antimanifesto no formato de grade de palavras que permitem todos os cruzamentos sobre o Wall Text: "ANARCHY TORTURE — AN ART KIT TORTURE — AN ART DEFECTOR », etc.

À primeira vista, e talvez a contragosto, mas na longa duração de sua inscrição, na qual a "pintura" não é matéria estranha, a obra de Buren poderia mesmo ser apreendida como uma maneira de levar ao seu maior limite em termos quantitativos a ruptura com a forma operada pelos papéis cortados de Matisse e a sua expressão no visível. Sobre estes papéis cortados, que "já apareciam como fogos de artifício no campo da arte de sua época", o próprio Buren afirma que eles "estilhaçam literalmente, caso o comparemos com os trabalhos de hoje" que fizeram sua "a ortodoxia da redução cromática sistemática" como se ali houvesse "antagonismo [...] entre pensamento e cor"; e de valorizar contra este novo academicismo minimal-conceitual da pureza o "princípio de que a própria cor é pensamento". Retomando sua evolução a este respeito, ele salienta que "esta preocupação com a cor sempre marcou [seu] trabalho e já estava aparente desde o início" (em meados dos anos 1960) embora "'encoberto' pelo discurso crítico"1 e sem dúvida também sob um intratável rigor estrutural mobilizado pela vontade de ruptura "epistemológica" com a imagem pictural do quadro e a necessidade de uma desconstrução completa da "história da arte (aquela das formas)"2. Uma coisa explicando a outra, o 
antiformalismo e o antiexpressionismo, que estão no princípio de toda o procedimento de Buren - e que poderiam imediatamente associá-lo à Matisse (ou a um pensamento-Matisse que ele, por outro lado, toma o cuidado de afastar da recepção francesa padrão que coloca Matisse "do lado da pintura-pintura"3) -, serão impulsionados até seu o limite quantitativo, fundado sobre o princípio da repetição das faixas verticais alternadas brancas/coloridas de $8,7 \mathrm{~cm}$ de largura. Destinada a Ihe "retirar qualquer significado de ordem emocional ou anedótica" 4 , a repetição será capaz de dar "um aspecto objetivamente diferente" a todas suas atualizações in situ: "é uma repetição com diferenças [... e] pode-se até dizer que são estas

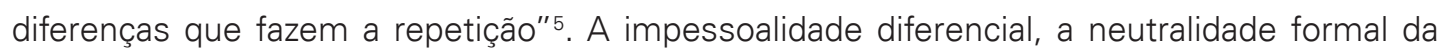
"ferramenta visual" assim definida é o signo de um dispositivo que deve ser chamado de pós-conceitual, como um deslocamento radical da antinomia do modernismo e do antimodernismo duchampiano. Ora, esta operação pós-conceitual sobre (e sob) a pintura (e seu contexto), parece-nos, envolve todo Buren pela crítica tanto inclusiva quanto exclusiva da arte conceitual na qual, para ele, ela está implicada ${ }^{6}$ desde o texto fundador, que terá numerosas variações, na forma de "Advertência" (Mise en garde) (no âmbito da exposição Konzeption/Conception de Outubro de 1969). O fato de que a questão ultrapasse o que comumente se diz em termos de "desconstrução da retórica da pintura" é confirmado, através de Matisse precisamente, em dois trabalhos de 1973/1974 e 1976 (este último retomado em 1984).

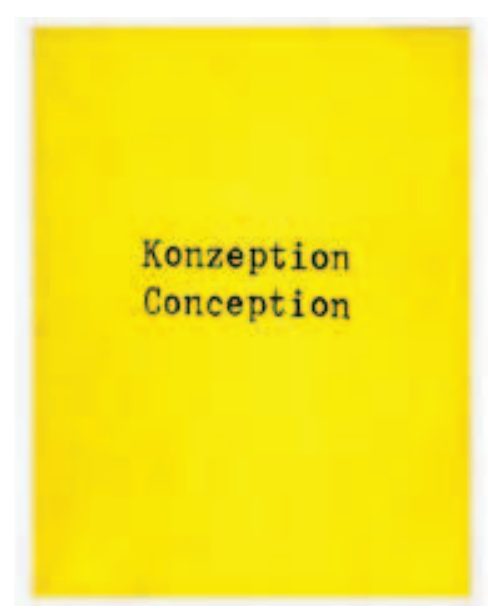

\section{Daniel Buren}

Capa do catálogo da exposição Konzeption/Conception de outubro de 1969 
O primeiro trabalho inscreve-se no contexto de uma exposição no Kunstverein de Colônia em torno da arte minimal e conceitual ("On Art: Kunst über Kunst", Abril de 1974). Ele consistia em recobrir as vigas de concreto da galeria com longas faixas listradas verticais brancas e vivamente coloridas, de mesma largura $(8,7 \mathrm{de} \mathrm{cm})$, cujas duas extremidades brancas foram recobertas com pintura igualmente branca — de acordo com o dispositivo "imutável" qualificado por Buren como "ferramenta visual (outil visuel)", mas inclinadas de modo diferente para cada lado, negando assim sua redução a um "puro conceito"7. Diferentes de uma viga à outra, as cores "foram colocadas seguindo a ordem alfabética das cores no vocabulário alemão"8, ou seja, na língua falada no lugar em que a obra é vista, e da esquerda para a direita em relação à entrada do visitante no espaço, coincidindo assim com o sentido da leitura. A discursividade das cores das quais se fala, para falar como Duchamp, é assim reenviada para o arbitrário do signo das cores (dos signos-cores) "indizivéis" (para falar desta vez com Buren) que vemos, dissociados de seus efeitos simplesmente retinianos ${ }^{9}$, "sobrevoar" toda a exposição como "uma espécie de festa do 14 de Julho" em virtude do contraste "muito violento", de muito mau gosto, entre as cores vivas e "o efeito camaïeu de referência cubista, que vai do branco ao preto, de todas as outras peças expostas embaixo"10. Além da autonomia absoluta das relações de cores diante da linguagem que as nomeia, esta referência ao cubismo (há muito tempo qualificada por Buren de "ordem repressiva"11) reintroduz através da faixa12 a relação com os "fogos de artifício" de Matisse na visualização do limite ilusionista e reificante do processo conceitual que reduz o próprio conceito a um objeto sem cor: "colocar uma ideia 'preto no branco' induzia de maneira quase literal a não introduzir a cor"13. A cor, o jogo readymade com as cores que não são menores e que não se escolhe ${ }^{14}$, torna-se assim o vetor de uma "pintura" pós-conceitual que desconstrói teoricamente a prática da pintura que ele confronta com a destruição de seu conceito referido a todos os seus "limites" constitutivos: sua diferença com a pintura do edifício, com a decoração e com o decorativo, seu estatuto de bem transportável e intercambiável que o integra na livre circulação das mercadorias ${ }^{15}$.

Livre circulação comercial, é necessário lembrar, à qual Buren opôs-se desde 1968-1969 pelo "Certificado de aquisição que deve acompanhar cada obra em circulação". Ele coloca nos termos de Advertência como sendo "inegável que este último [DB] deve poder manter o controle do uso que pode ser feito do seu nome" e de sua obra: proibição de reproduzir "ou deixar reproduzir por qualquer meio" e de toda "exposição pública da obra adquirida [...] 
salvo autorização prévia e escrita por Daniel Buren". Tantas obrigações vinculativas às quais o adquirente subscreve reconhecendo que "ele pretende pagar por isso, efetivamente, um valor de mercado pela obra adquirida, ao qual a obra adquirida permance principalmente estranha"16. Portanto, ela não será mais assinada com o nome de Buren, mas terá apenas um Certificado-Advertência (assinado somente com nome do adquirente) que "não prova nada senão a proveniência da obra à qual ele se refere" e não pode em nenhuma hipótese ser um substituto da obra a qual, ademais, "nenhum marchand, nem intermediário ou terceiros quaisquer [...] estará habilitado a autenticar"17. Mede-se aqui a diferença crítica da arte conceitual que pretendia, pela desmaterialização linguística do objeto e a redução de sua visualidade a uma matéria cinza, escapar ao seu estatuto de mercadoria e à sua forma (ou ao menos a seu circuito) de distribuição. (Mas e a desmaterialização do dinheiro? ${ }^{18}$ pergunta Buren.) Resulta que é necessário voltar à pintura em uma "pintura" pós-conceitual. Os papéis cortados de Matisse podem também aparecer como o alargamento mais promissor da "fissura" introduzida por Cézanne na história da arte e uma primeira saída, mesmo que demasiada "empírica" e "parcial", à oscilação constante entre os "dois polos simbolizados por Cézanne e Duchamp" que comandam a "história da arte contemporânea"19.

O segundo trabalho foi realizado em analogia direta ao grande guache cortado de Matisse, $O$ periquito e a sereia (La Perruche et la sirène,1952), peça principal da coleção permanente do Stedelijk Museum de Amsterdam, da qual Buren vai se servir como se fosse uma palheta para interferir no espaço, após tê-la decomposto em todas as suas cores e determinado sua frequência de aparecimento. Reduzidas assim a uma pura amostragem (ou padronização ${ }^{20}$ ) cores foram transferidas para peças listradas que coincidem com a forma de um elemento arquitetônico: aquela de dois triângulos com base curvilínea que enquadram o arco pleno das portas e dos nichos cegos. Esta intervenção destaca assim em positivo áreas exclusivamente decorativas que não têm vocação para atrair a atenção, obedecendo, ao mesmo tempo, o princípio da incisão ("eu faço uma incisão de formas diretamente projetadas na parede") de um desenho/recorte, considerado, ademais, "muito próximo" do "procedimento dos papéis cortados" 22. As cores foram "distribuídas simetricamente e por ordem decrescente" de modo que, "como em um espelho, [elas] correspondam-se em relação ao eixo central do museu, de um lado ao outro da grande escada de entrada"23. Mas uma vez que os dois triângulos que arrematam cada nicho são de cores diferentes, o dispositivo acaba por introduzir uma 
dissimetria na simetria, desudando-a de maneira tão violenta que as altas cimalhas do museu parecem de um brancura quase imaculada, sendo destacadas por grandes nichos cegos que enquadram as telas. (O trabalho não será repetido à toa, em1983, no mesmo museu de Amsterdam sob o título Kaléidoscope.) A maneira como o museu enquadra(-se) e expõe as obras, terminando por fazer da "exposição de uma exposição" a obra de arte por excelência, é ela mesma exposta e voltada contra o museu pela função crítica des-enquadrante do dispositivo. Como que clinicamente, ela é relançada numa topografia como after Matisse quando Buren projeta "decorativamente" sobre todas as paredes do museu as cores-de-Matisse desterritorializadas "em objetos parciais plurívocos, moleculares, que se dividem ou se multiplicam incessantemente, escapando assim à hierarquia como o contrário do objeto inteiro (a tela por excelência) que a implica e, por isso, submete-a à ilusão de um todo harmonioso e acabado" 24 . Porque é também a exposição da exposição (ou da "entrada") no museu do grande papel colado de Matisse, "explodindo em cor" 25 e radicalmente estranho por sua decoratividade ("superior") tanto à forma-objeto do quadro quanto à qualquer exposição puramente museológica ${ }^{26}$, que é portanto mostrada e des-mostrada pelo anonimato calculado da "ferramenta visual" com listras que empregam ao pé da letra o seu uso espacial decorativo menos nobre e mais comum. "O papel estético do Museu" é denunciado ali por contraste como "ponto de vista único (cultural e visual) a partir do qual as obras podem ser apreendidas" 27 e mais geralmente como o "revelador comum" ${ }^{28}$, essencialmente conservador, de toda forma de arte ao que for equivalente, quando qualquer pintura ou não-pintura (Matisse) ou objeto-readymade (Duchamp) funcionar como "decoração" de um suporte cuja presença é tão mais real que é ignorada quando ela expande invisivelmente seu ponto de apoio "idealista" sobre "todo objeto transportado" ou transportável, ou sobre "qualquer discurso [...] que se inscreva no lugar Museu"29.

Consequentemente, a crítica do sistema Museu/Galeria é acompanhada de uma crítica complementar da "função do atelier" como "lugar fixo de objetos obrigatoriamente transportáveis" e "butique [do] prêt-à-porter a expor [...] como objeto manipulável ao infinito e por qualquer um". Esta crítica do atelier faz parte do circuito museu/galeria onde as obras, mais do que serem expostas, vão ser alojadas ("e o que é alojado não está próximo de se estabelecer?") e leva, na sua "abolição" ${ }^{30}$, até os promotores minimalistas/conceituais do Mito Duchamp. (Lembremos que o "instalador de papel parisiense" — como Donald Judd qualificava Buren 
- realmente foi uma criança pós-conceitual na costas do Minimalismo e da arte conceitual durante sua famosa intervenção, proibida pelos defensores de um e da outra, no Guggenhein Museum: Pintura/Escultura, 1971).

Mas o "signo-ferramenta" não se limita a tornar visível o lugar onde ele desenvolve-se (site specificity) e/ou a produzir a crítica (a crítica institucional), mas torná-lo opaco tomando como base a passagem da insignificancia (do signo-objeto) à assignificância do signo esvaziado da sua última significação = grau 0 da pintura pela matéria visual que está suficientemente liberada dele para apresentar, a quem quiser ver, todas as circunstâncias de sua visualização. De um signo ao outro, não é difícil antecipar que a dialética - que é colocada entre a ferramenta visual e sua situação que se torna o acidente em relação ao lugar (em todos seus componente) - vai reter o acidente como a própria "proposição" do in situ e ser animada por uma tensão diagramática eficaz dos efeitos que vão trans-bordar as "cores" do projeto assim lançado. Tornando-o clinicamente mais imprevisível - e menos imediatamente legível em uma perspectiva crítica.

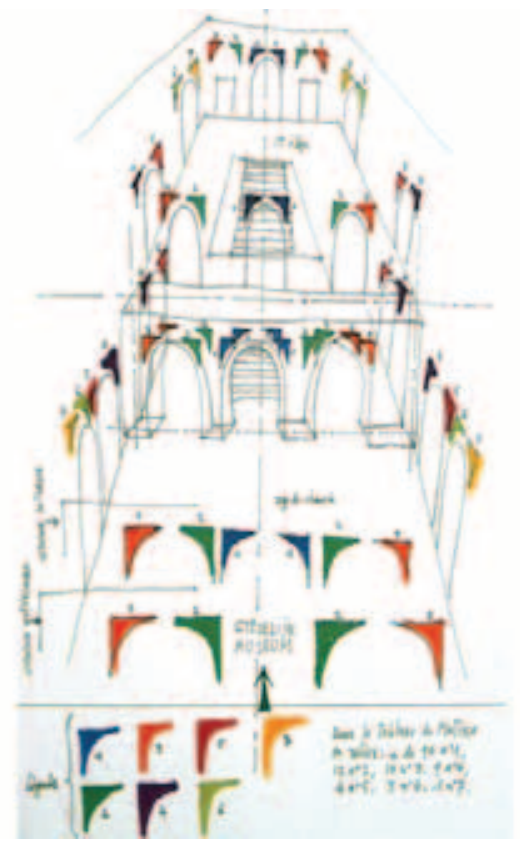


Sobre o trabalho in situ de Buren, Bernard Blistène escreve que "não é tanto um trabalho com a arquitetura, mas 'sobre' e 'sob' a arquitetura" no sentido de que Buren não trabalha "tanto para a arquitetura quanto a despeito e às custas dela, e [...] o que ele não elabora não é tanto uma meta-arquitetura mas uma não-arquitetura" ${ }^{31}$. Uma não-arquitetura sem dúvida, mas que não ataca diretamente a arquitetura em seus "limites formais e culturais" uma vez que a análise e a desconstrução destes ("e não um ou o outro") são o fato de uma crítica "institucional" da arte (endereçada a esta última ${ }^{32}$, e não à arquitetura como tal). Atacar, ao contrário, os limites da própria arquitetura, confrontá-la no ponto clínico (ou entrópico) de seu colapso material e levá-la até o ponto crítico do colapso ideo-lógico de sua economia - isso foi a primeira função do antitrabalho arquitetônico= "anarquitetônico" de Gordon Matta-Clark que pressupõe a destruição da "obra (work)" (do edifício abandonado destinado à sua destruição, levando com ela todas as intervenções da arte da qual ele será menos o "site" do que o "non-site" e a sede). A afirmação do caráter social ("to deal diretly with social conditions"3") desta destruição transformada em desconstrução (unbuilding) por cortes (cut out, cut up, cut away, cut through...) aplicados ao edifício em uma ontologia experimental do espaço urbano vale diretamente como ruptura com a Land Art ("literally like drawing on a blank canvas ${ }^{34 ")}$ e com a Arte Conceitual ("Rather than using language, using walls"35). Des-fazer a parede para liberar performativamente e de modo efêmero o espaço social de seus "limites arquitetônicos" 36 e de sua dialética opressiva do privado/público: é neste novo sentido que Gordon Matta-Clark poderá empregar o termo de "não-arquitetura" 37 para marcar a dimensão crítica de seus projetos no que diz respeito à função social da arquitetura que é contrainvestida, ao mobilizar toda sua semiogênese capitalista (que é, sob a alcunha de "urbanismo", o plano de consistência real da arquitetura).

Dito isso, torna-se necessário rapidamente esboçar um duplo jogo de consequências pós-conceituais.

1/ Se a "não-arquitetura" implicada pelos cortes opera criticamente em um edifício que nunca está "nu" mas semiologicamente estratificado (analisável ao longo de uma verdadeira investigação, até seu "abandono") no meioambiente sem fora do qual ele participa como site/non-site, o non-site deverá, como tal, ser clinicamente elevado a um estado socialmente "anarquitetônico". Longe de qualquer "solução" (ou/e "end product"38), ele não propõe um uso alternativo à compartimentação do espaço, mas o diagrama com uma nova enunciação 
espacial a partir dos "vazios metafóricos, interstícios, espaços abandonados, lugares que ainda não foram explorados ${ }^{39 ", ~ e ~ q u e ~ f a z e m, ~ t o d a v i a, ~ r e f e r e ̂ n c i a ~ a o ~ e s p a c ̧ o ~ r e a l ~ o n d e ~ n o s ~ d e s l o c a-~}$ mos: como a "pontuação desestrutural (destrutural puntuation ${ }^{40}$ )" de um "espaço-movimento (movement-space)" tornado "significativo" pelas "interrupções" cotidianas que o animam¹. A lição da arte conceitual é registrada aqui para ser levada à sua mais alta potência em um movimento de socialização que passa pela sua radical desfenomenologização.

2/ A ontologia espacial trazida pela anarquitetura desloca a pluralidade dos seus meios de expressões (físico-arquitetônico, evento-performativo, fotográfico, fílmico...) em uma re-construção, diferencialmente articulada e explodida de sua matéria enunciativa trazendo um alcance "transcategorial" a seus recortes - arriscando uma palavra que atravessa de uma maneira cut-up os recortes ambientais de Matisse pelo corte do campo da arte (ao qual é historicamente associado Duchamp do signo). Pois não é a multiplicidade dos modos de espacialização que é próprio a Matta-Clark: esta participa da des-ontologia conceitual e de suas sequências non-sites specifics (pensando em Robert Smithson ou Dan Graham); é seu agenciamento em forma de des-montagem vertiginosa que, mais "significativamente", reenvia as fotomontagens (que podem integrar ou esculpir fragmentos de películas foto ou de filme) ao choque experimental dos edifícios cortados (ao qual o visitante não poderia escapar, sob risco de "cair nos cortes [praticados por Matta-Clark] (falling through his cuts ${ }^{42}$ )"). Mas este último é totalmente desterritorializado em procedimento semelhante de desmultiplicação dos planos de corte que aparecem como o produto do que Matta-Clark denomina "spatial drawing" e que deve ser concebido como um radical e diagramático desfazer (a imagem — da) escultura que inclui sua crítica pela arte conceitual. Pois um e outro estão fechados ao projeto de uma "arqueologia viva (living archeology ${ }^{43}$ )" da fábrica social da cidade (Matta-Clark diz e escreve "urban fabric": o tecido urbano).

Pois, decididamente, será necessário a hipercomplexidade das fotomontagens cibachrome de grande formato às quais Matta-Clark, então, entrega-se para nos projetar através de Office Barroque (Antuérpia, 1977) e de suas superposições de planos que se emaranham de uma maneira indescritível a partir do ponto de vista não mais rigorosamente vertical: os cortes se recortam entre si, as vigas conservadas os barram suscitando ângulos de visão divergentes (por cima /por baixo) que acentuam os fenômenos (visto-)de cima, portas que batem no vazio tomadas em uma "panoramica de arabescos" que apenas podem ser vistas através da 
colagem em 45 graus de duas fotos... As conexões enviesadas dos negativos terminam por revirar o espaço, alucinando todas as suas direções (até fazer a fachada desmontada/remontada dançar em uma sequência de fotos tomadas de fora com vistas para o interior), as perfurações deslocadas das bordas das fotos vizinhas fazem os planos deslizarem e entrarem em fricção (como em um tempo cinemático abstrato com durações compostas), enquanto que as cores Cibachrome artificialmente montadas terminam de des-realizar a cena superexpondo com a coreografia dos cortes/cuttings que não são tanto fotografados, mas fotograficamente prolongados e intensificados ou "revelados" nas montagens - a sua inquietante estranheza. Mais distante possível de toda fenomenologia (do corpo vivido), é então um corpo totalmente des-territorializado pela força de desorientação espaço-temporal amplificada pelo processo trans-media - ao qual o observador é confrontado (e que não pode ignorar off site) - que é mobilizado e que anima o espaço mis en abyme com sua energética abstrata-concreta.

A recusa do snapshot à qual Matta-Clark foi conduzido por toda sua prática, e que o leva cada vez mais a não utilizar planos fixos senão (des)montando-os e artificializando suas cores, deixando visível ao mesmo tempo as perfurações das películas (dependendo da de-monstração ou da des-definição destas fotos com respeito à sua função indicial e documentária), marca também o maior distanciamento da "retórica da indiferença" própria ao fotoconceitualismo da qual ele pôde adaptar à folha de estilo para desviá-la de seu uso. (Pensar-se-á, mais particularmente, sobre o agenciamento fotográfico preto e branco de Reality Properties: Fake Estates [1974]: estas minúsculas parcelas de terreno nas margens da calçada ou entre dois imóveis adjacentes existentes na cidade e que Matta-Clark adquiriu. Ele apresentara as fotografias documentais acompanhadas do título de propriedade com seu nome e uma planta dos lugares). Na verdade, a imagem não é mais desfeita do exterior e por neutralização de todos seus efeitos não documentais. Ela é desfeita pela precipitação do observador no splitting des-multiplicado de um "interior" tornado assim inabitáve/ pela projeção em forma de montagem hiperconstrutivista dos cuttings desconstrutivos dos edifícios que se tornam estes quase-corpos que o canibaliza ao desterritorializa-lo "around and in the round" (de acordo com a expressão de Briony Fer ${ }^{44}$ ). Pois este "round" foi tão visivelmente manipulado que ele perturba até a presença daquele ter-estado-ali que é ligado à fotografia: ela não é mais a forma-signo de uma irrealidade real que organiza - fosse isso como o que resta - o acesso ao estar-ali "natural" dos ob-jetos no espaço, mas a força-signo de uma real irrealidade a qual todo 


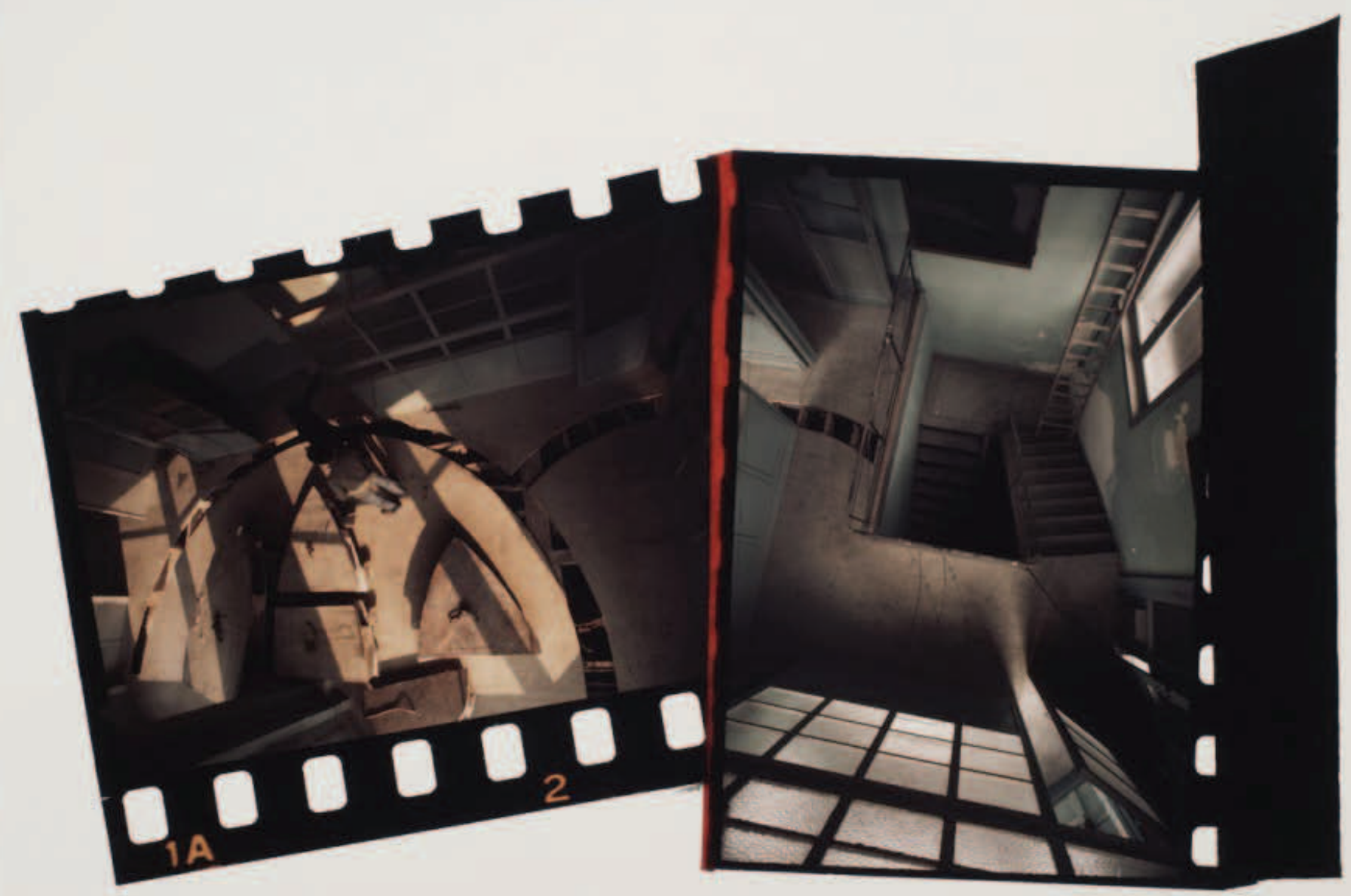

Office Baroque, 1977

Silver dye bleach print (Cibachrome)

83.8 x $109.2 \mathrm{~cm}$. Cortesia da David Zwirner Gallery 
dispositivo do unbuilding desmontou a gênese, implicado nisso a organização do território do presente em termos de "ruínas iminentes". Não é esta iminência que está totalmente em jogo na perda de referência ("indicial") das fotografias (de "throw-aways"45) cuja montagem vale por de-monstração crítica do seu non-site You have to walk, na pós-história que é a nossa (a pós-história como história do non-site), e diante destas fotomontagens que sabem nos encontrar ali nos reanimando com seu quase-corpo? Compreende-se, então, porque era necessário a subversão meta-física da ótica fotográfica nas fotomontagens que contradizem a suposta transparência do médium para re-presentar um espaço que não se dá senão para nos perder no "círculo" de suas desconstruções e de sua destruição programada que barra seu "acesso". ("You have to walk" (through), repete incessantemente Matta-Clark - but we can't (get in), and he knows it.). Ao excluir qualquer "snapshot scenic work", "desafiando a qualidade de objeto próprio da escultura" (mesmo alargada ${ }^{46}$ ), é o engajamento nesta inacessibilidade que é, em última instância, fotomontada e que nos é proposta como desmontagem de uma arquitetura elevada à sua potência pós-conceitual.

O que se verifica pela radicalização de Office Barroque que abre espaço para sua última intervenção: Circus ou The Caribbean Orange (Chicago, 1978). Tudo se passa como se, por uma transducção, ao mesmo tempo diagramática e cinestesicamente sensível, o edifício passasse para uma nova (quarta) dimensão na qual ele tivesse apenas espaços negativos em colisão de escalas e sem mais nenhum eixo perpendicular para manter de pé o monumento. É este efeito de espaço com curvatura variável do nonument que será experimentado como nunca pela complexidade das fotomontagens que Matta-Clark chama agora de "photo-works" no sentido, explica-nos, de que "eles utilizam a obra como uma espécie de cena lpara si próprios e] para isso (They use the piece as [a] kind of stage for $i t^{47}$ )." A autonomia selvagem dos photo-works ("they use...") obtida pela "colagem e montagem (collaging and montaging)" apropria-se, assim, da ruptura anarquitetônica que elas cenografiam, começando por violar o princípio sacrossanto ("documental") do enquadramento fotográfico: "I like very much the idea of breaking - the same way I cut up buildings. I like the idea that the sacred photo framing process is equally 'violatable'48". Engajando uma desterritorialização maquínica absoluta do espaço do qual não se sabe definitivamente mais nem o que é nem onde está, o des-enquadramento da (contra)-fotografia expropria em seu benefício os cortes do site/non-site tornados meios da fotomontagem, excluindo qualquer documentação de um percurso 


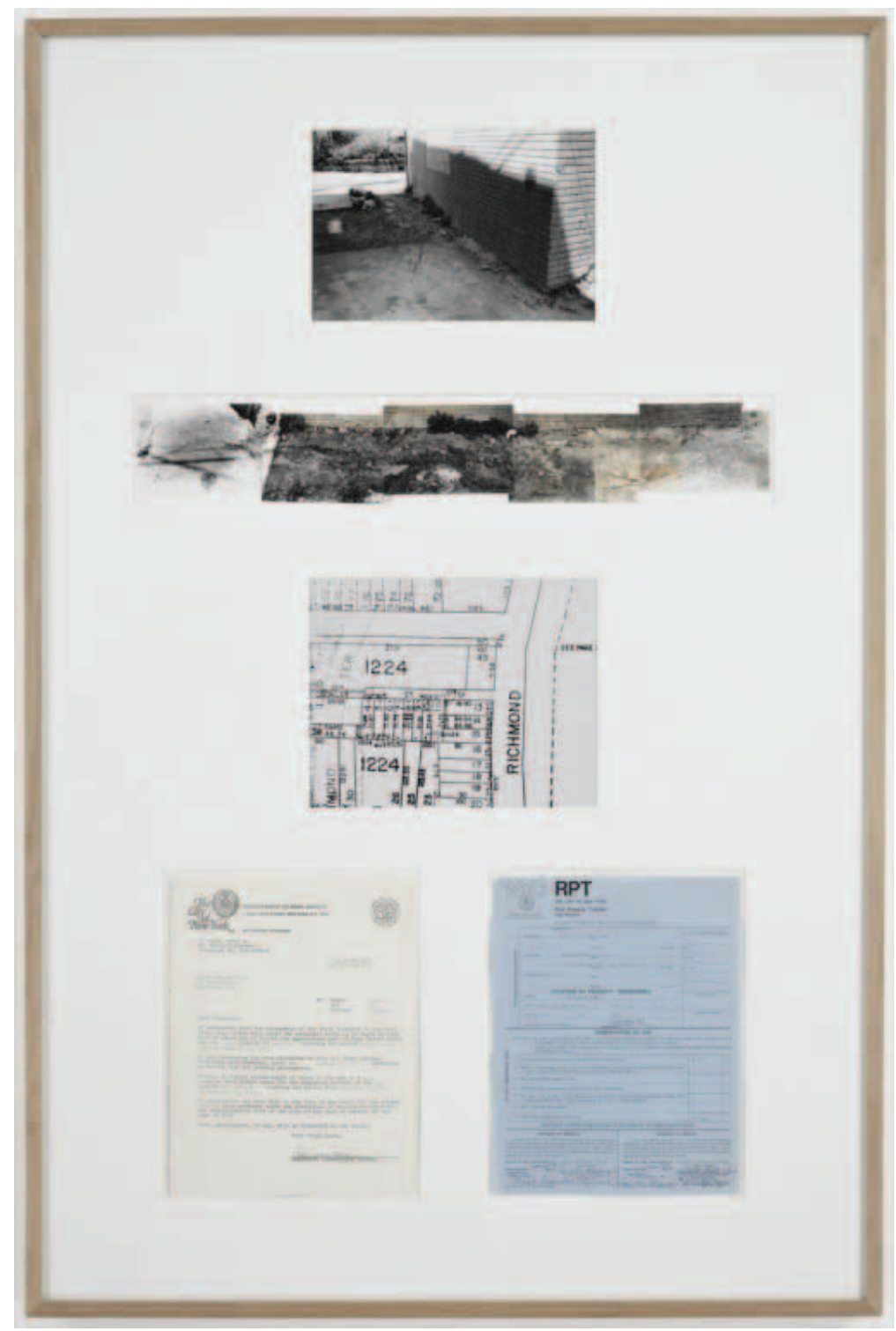

Reality Positions: Fake Estates, "Staten Island," Block 1224, Lot 12, 1978 Collaged gelatin silver prints, deed, and documents $113 \times 74.9 \mathrm{~cm}$. Cortesia da David Zwirner Gallery 
em tensão ótico-cinestésica. Os visitantes são, eles próprios, tomados in situ nos meios de produção de um tal dispositivo dos quais se tornam um componente. E é, exatamente, o que se vê nas fotomontagens cibachrome de películas nas quais as figuras humanas, suspensas nos espaços incertos, não são mais portadoras de um campo de visão (des)contínuo, ou de qualquer possibilidade de penetração do espaço que elas compartilhariam conosco. Elas não são mais do que índices das manipulações de escala e as testemunhas da inabitabilidade do não-lugar que se abre diante delas em planos-cortes sobredesmultiplicados pela justaposição das fotos e pela rotação das fitas adesivas coloridas em torno delas ${ }^{49}$. No que talvez seja o mais característico do cibachromes de Circus, composto da montagem na vertical de duas fotografias cuja junção abaula o espaço, ao mesmo tempo que o cinde com um corte ultrafino na junção, percebe-se, duplicada pela cesura do cut-up, a faísca de um flash dissimulando o fotógrafo ${ }^{50}$. Pelo espelho que é assim colocado à nossa frente, ele se coloca no nosso lugar no "tempo real" que é este ao qual ele nos introduz no "círculo" entrópico da operação. Se "circo" significa "círculo" na linguagem "disléxica" de Matta-Clark, é um "Circo de inverno (winter circus)" que tem do Sul ${ }^{51}$ apenas a textura colorida e quase gelatinosa nos distintos lugares das ampliações em cibachrome, com as franjas de cores que eles organizam e sobre as quais estão dispostos: o que Matta-Clark chama um "novo vocabulário da cor", que ele pretende "desenvolver como parte integrante de seu trabalho" 52.

\section{Notas}

1 BUREN, Daniel, Au sujet de... Entretien avec Jérôme Sans, Paris: Flammarion, 1998, p. 176-177 (as citações anteriores são retiradas destas páginas).

2 Daniel Buren, Repères (1970), BUREN, Daniel. Les Écrits 1965-2012, vol. 1 : 1965-1995. Sous la direction de Marc Sanchez. Paris : Flamarion : 2012, p. 144 ; p. 150. (A partir de agora esta obra virá abreviada como DB1).

3 Daniel Buren, Entretien avec Bernard Marcadé (1986), DB1, p. 1146. Buren opõe a esses Franceses "estrangeiros [que], ao contrário, veem no trabalho de Matisse elementos que dependem da ideia, do pensamento" (grifo nosso). Permitindo-nos acrescentar que nosso Pensamento-Matisse, vinte anos mais tarde, é exceção que confirma esta "regra" (cf. E. Alliez, J.-Cl. Bonne, La Pensée-Matisse, Paris, Le Passage, 2005).

4 Daniel Buren, Mise en garde (1969), DB1, p. 82

5 Ibid., p. 84. Impossível aqui de não assinalar a convergência com o pensamento deleuziano tal como se formula em Différence et répétition, publicado em 1968. 
6 Ver a formulação particularmente sintética que Buren propõe em uma entrevista de 1991: "A questão muito inteligente e interessante da dita arte conceitual [...], é recolocar o objeto em questão. [...] A única diferença em relação a mim, é que penso que este questionamento deve ser feito pelo viés do objeto, e certamente não através de seu desaparecimento", cf. Buren par la bande (1991), DB1, p. 1734.

7 O que é devidamente evidenciado no texto para o catálogo da exposição, cf. Daniel Buren, À propos de..., DB1, p. 354-55 (com foto de Daniel Buren, Mot à Mot, Paris, Centre Pompidou, Éditions Xavier Barral, Éditions de la Martinière, 2002, C 96 / Couleur).

8 Daniel Buren, Au sujet de..., op. cit., p. 175. Este procedimento alfabético será rapidamente generalizado por Buren.

9 Cf. Daniel Buren, Au sujet de..., op. cit., p. 180: “Há razão para se desconfiar dos 'danos' da cor, a começar pelos efeitos retinianos contra os quais Duchamp já nos advertia!" E também acrescentanda por toda a prática de Matisse, acresentariamos nós.

10 lbid., p. 175 .

11 aniel Buren, Repères (1970), DB1, p. 149. Com o que podemos apenas concordar plenamente, cf. Éric Alliez, Jean-Claude Bonne, La Pensée-Matisse, in : Le Passage, Paris, p. 27 sq.

12 N.T. Aqui Alliez propõe um jogo de palavras impossível de reprodução em português: par la bande = en contrebande.

13 Daniel Buren, Au sujet de..., op. cit., p. 179. Para a crítica do "conceito" da arte conceitual colocando "no nível do objeto, o conceito propriamente dito" e reduzindo-o consequentemente a um "conceito-objeto", cf. Id., Mise en garde, DB1, p. 77. Significativemente intitulado "En regard" e datado 1979/1980, a última versão de "Advertência" explicita que esta "visaria muito particularmente tudo o que se faria coma nova mercadoria sob a etiqueta de 'Arte conceital'" com a "multiplicação de objetos de valor medíocre", etc. (/d., En regard, DB1, p. 729-730). "A fetichização mesma estaria na raiz da Arte conceitual", retoma ainda Buren em sua Entrevista com Michel Parmentier e Anne Baldessari, cf. Daniel Buren, Michel Parmentier, "Propos délibérés" in Art édition, Lyon, 1991, p. 106. Daí que ele teria sido "acadêmico desde a origem", cf. Id., Fonction d'une exposition (1973), DB1, p. 344.

14 “Daniel Buren toma suas cores sem as escolher » era o título do primeiro artigo publicado sobre seu trabalho. Datado de 1965 e assinado por Sarane Alexandrian, ele abre Les Écrits (DB1, p. 15-16) sob o signo do arbitrário e da exclusão do gosto, permitindo utilizar de maneira mais objetiva as cores sem eliminar as relações que elas podemter entre si.

15 Observar, ainda sobre esse último ponto, o estatuto à parte dos grandes papéis recortados de Matisse.

16 Daniel Buren, “Certificat d'acquisition n..., DB1, p. 91-95.

17 Daniel Buren, Avertissement, reproduizada em fac-simile em ld., Mot à Mot, op. cit., A 50 / Avertissement.

18 Cf. Maria Eichorn, "On the Avertissement: Interview with Daniel Buren", in John C. Welchman (éd.), Institutional Critique and After, Zurich, SoCCAS - JPR Ringier, 2006, p. 98. O que levou Buren a definitivamente preferir a Advertência ao Certificado, que poderia ainda conceitualmente substituir a obra e sua fisicalidade. Deve-se saber que Rolf Wedewer, em sua Introdução para o catálogo da exposição Konzeption/Conception (1969), definiria muito precisamente a arte conceitual pela substituição da obra (de arte) pelo projeto (descrição, croquis) dotando a obra "de importância secundária" que pode nem ser realizada, cf. Rolf Wedewer, "Introduction to Konzeption/Conception", in: Alexander Libero and Blake Stimson, Conceptual Art: A Critical Anthology, Cambridge - Londres, MIT Press, 1999, p. 142-143. (A advertência é, ainda hoje, utilizada por Buren "por ocasião de qualquer transação.")

19 Ibid., DB1, p. 156-157. Nesta passagem, Buren cita Matisse ao lado de Mondrian, Pollock, Newman, Stella..., a saber, estes que souberam alargar a "fissura" cezaniana 
20 N.Y. O termo é étalonage que por sua vez reenvia à obra de Duchamp 3 stoppages étalon

21 Seguindo um gesto cujo princípio e a destinação arquitetônica poderão denominar os Ten Large Color Panels (250 x 950 cm) de Gerhard Richter (1966-1971/2).

22 Daniel Buren, "Entrevista com Anne Baldessari” (1986), DB1, p. 1200.

23 Daniel Buren, Au sujet de...,op. cit., p. 178.

24 Daniel Buren, "Anatomie" (1976), DB1, p. 500.

25 Daniel Buren, "Sur Matisse" (1993), DB1, p. 1853

26 "Estes pápeis, sobretudo aqueles de grandes dimensões, o Museu transforma-os de papelão (esboços) em telas (pinturas)", e isso "sob uma espessura tripla de plexi", cf. Daniel Buren, Michel Parmentier, Propos délibérés, op. cit., p. 101. Os pápeis recortados foram assim "desnaturalizados pelos museus de arte moderna" (Daniel Buren, "Entrevista com Anne Baldessari", DB1, p. 1202).

27 Daniel Buren, "Fonction du Musée" (1970), DB1, p. 162.

28 Daniel Buren, “Limites critiques" (1970), DB1, p. 171

29 Cf. Daniel Buren, “Fonction du Musée", DB1, p. 162.

30 Daniel Buren, "Fonction de l'atelier" (1971), DB1, p. 185-194

31 Bernard Blistène, "Daniel Buren, l'artiste, I'architecte et le géomètre" in: Annick Boisnard, Daniel Buren, Cabanes éclatées. Catalogue raisonné thématique, vol. 2, Le Bourget, éditions 11/28/48, 2000, p. 7.

32 Cf. Daniel Buren: "A arte é exclusivamente política. Impõe-se então a análise dos limites formais e culturais e não um ou outro no interior dos quais a arte existe e se debate." (/d., "Limites critiques", 1970, DB1, p. 180).

33 Ver a entrevista com Donald Wall, "Gordon Matta-Clark's Building Dissections", Arts Magazine, May 1976, republicada em Gordon Matta-Clark. Works and Collected Writtings, ed. Gloria Moure, catálogo de exposição, Barcelona, Ediciones Poligrafa - Museo Nacional Centro de Arte Reina Sofia, Madrid, 2006, p. 61; trad. fr. de Raphaëlle Brin, in Gordon Matta-Clark, Entretiens, Paris, Éditions Lutanie, 2011, p. 73.

34 Na mesma entrevista: "Minha escolha de trabalhar com o meio ambinete urbano de modo geral e as estruturas dos edifícios modificou todo meu sistema de referencia et me afastou da nobre temática dos grandes espaços naturais vazios que, para os artistas da Land Art são as telas brancas sobre as quais se pode desenhar." A entrevista prossegue: "Eu escolhi, ao contrário, não me isolar das condições sociais existentes, e de trabalhar diretamente com elas (to deal directly with social conditions)." (WCW, p. 61 / E, p. 73).

35 Gordon Matta-Clark, "Completion through removal," Catalogue entry, semdata, WCW, p. 89.

36 Gordon Matta-Clark, "The earliest cutout works", sem data, WCW, p. 136

37 Entrevista com Liza Bear, “Gordon Matta-Clark: Splitting the Humphrey Street Building," Avalanche, December 1974, republicada em WCW, p. 166 / E, p. 10

38 De acordo com o testemunho de Tina Girouard sobre o Anarchitecture group formado por Matta-Clark ao lado de Suzanne Haris e Tina Girouard, e que estava aberto a outros participantes (Laurie Anderson, Caroline Gooden, Jeffrey Lew, Richard Nonas...). Cf. Gordon Matta-Clark: A Retrospective, catálogo de exposição, Museum of Contemporary Art, Chicago, 1985, p. 121. Pode-se ler em uma nota de cabeçalho "anarchitecturale": "Solutions are the weakest forms at work" (WCW, p. 383). 
39 Entrevista com Liza Bear, ibid. (WCW, p. 166 / E, p. 11). Matta-Clark apresenta assim o "programa" do coletivo Anarchitecture. Em sua transformação anarquitetônica, o Non-site não é mais a galeria (onde se expõe o que aconteceu sobre o lugar de intervenção, como em Smithson) mais um espaço de discussão e de proposições coletivas, ou seja, um espaço-tempo de problematização.

40 Gordon Matta-Clark, "Cutting through for surprise", Notebook 1261, ca. 1970, WCW, p. 122.

41 Entrevista com Liza Bear, ibid. (WCW, p. 166 / E, p. 11). O exemplo proposto é do lugar onde você pode parar para amarrar seu sapato. Para este humor tão duchampiano, trata-se de ridicularizar, ao mesmo tempo, as "ideias" de funcionalismo e de formalismo, ou seja o caráter principal da arquitetura moderna desde Le Corbusier.

42 Marianne Brouwer, "Laying Bare", in Gordon Matta-Clark, éd. Corinne Diserens, catálogo de exposição, IVAM (Valence) — Musée Cantini (Marseille) - Serpentine Gallery (Londres), 1993, p. 363 (nós seguimos a edição francesa, Musées de Marseille). O que aconteceu a Lawrence Wiener, que realmente caiu (sem gravidade) durante sua visita no último edifício investido por Matta-Clark, Circus: Caribbean Orange (1978), alguns meses antes da morte precoce do artista, de um câncer do pâncreas, com trinta e cinco anos.

43 Ann-Sargent Wooster, "Gordon Matta-Clark", Art News vol. 75, n 8, October 1976, p. 124 (a epressão é dada como sendo do Matta-Clark: "in his own words"), citado par Briony Fer, "Graphic Strategies from Matta to Matta-Clark", op. cit., p. 42.

44 Briony Fer, ibid. Nós utilizamos aqui sua expressão em um sentido muito mais "desterritorializado" do que o que ela prega, determinado pelo que ela denomina ainda "the precarious phenomenological experience of the Cibachromes" (p. 141).

45 De acordo com a expressão de Matta-Clark em sua entrevista com Judith Russi Kirshner (fevereiro 1978), WCW, p. 318 / E, p. 111 ("Bom para jogar fora").

46 Ibid. WCW, p. 319: "even with the people who have escaped the so-called 'sculpture habit' by going into some sort of landscape, or extra-gallery, extra-museum type of territorial situation" (E, p. 115).

47 WCW, p. 333 / E, p. 142 (grifo nosso).

48 WCW, p. 332 / E, p. 140. Daí a "clara distinção entre photo-works e fotografias documentais".

49 Cf. Gordon Matta-Clark, ed. Corinne Diserens, op. cit., fig. 171, p. 124-125; sobre a vista aérea do negativo da direita, figura uma escala ao lado de um homem (Circus, 1978, Cibachrome, 24,8 x 101,6 cm).

50 Gordon Matta-Clark: A Retrospective, fig. 107, p. 115.

51 "Todo mundo diz que os circus descem para o sul no invreno, não é mesmo? Então, é um circo de inverno." WCW, p. 328 / E, p. 130

52 Gordon Matta-Clark, Carta para Valkanas, citada parThomas Crow, op. cit., p. 126 